\title{
"TU NÃO FAZES NADA ALÉM DE ARTE?" UMA ANÁLISE PSICODINÂMICA DO TRABALHO ARTÍSTICO
}

\author{
"DO YOU DO NOTHING BESIDES ART?" \\ A PSYCHODYNAMIC ANALYSIS IN ARTISTIC WORK
}

\begin{abstract}
MONIQUE NASCIMENTO
Universidade Federal de Santa Catarina (UFSC)

Doutoranda em Administração pela Universidade Federal de Santa Catarina (UFSC)

Orcid: https://orcid.org/0000-0003-1862-4295 / E-mail: moniquenn@gmail.com

Endereço: Rua Eng. Agronômico Andrei Cristian Ferreira - Trindade, Florianópolis - SC.
\end{abstract}

\section{ELOISE HELENA LIVRAMENTO DELLAGNELO}

Universidade Federal de Santa Catarina (UFSC)

Doutora em Engenharia de Produção (UFSC)

Orcid: https://orcid.org/0000-0001-7586-0302 / E-mail: eloiselivramento@gmail.com

\author{
MARINA COELHO \\ Universidade Federal de Santa Catarina (UFSC) \\ Doutoranda em Administração pela Universidade Federal de Santa Catarina (UFSC) \\ Orcid: https://orcid.org/0000-0002-2325-9985 / E-mail: marinacoelho.nina@gmail.com \\ Submissão: 05/08/2019. Revisão: 21/05/2020. Aceite:11/06/2020. Publicação: 03/08/2020. \\ DOI: http://dx.doi.org/10.22277/rgo.v13i3.5343
}

\begin{abstract}
RESUMO
Propõe-se, neste estudo, refletir sobre o trabalho artístico, com foco nas vivências de sofrimento, tendo por base entrevistas semiestruturadas em profundidade e observações do cotidiano de quatro artistas atuantes na grande Florianópolis/SC. Analisou-se as experiências de sofrimento vivenciadas por estes trabalhadores à luz do arcabouço teórico da psicodinâmica do trabalho e de literaturas concernentes ao trabalho artístico. Percebeu-se que estas podem ser relacionadas às condições de trabalho a que estes artistas estão submetidos, bem como ao não reconhecimento de sua atividade enquanto trabalho, circunstância que tende a dificultar a intensificação de processos sublimatórios e a resultar no agravamento das vivências de sofrimento.
\end{abstract}

Palavras-chave: Sofrimento no Trabalho. Trabalho Artístico. Psicodinâmica do Trabalho.

\begin{abstract}
In this paper, it is proposed to reflect about the artistic work, with the focus in the experience of suffering, based on in-depth semi-structured interviews and observation of four artists working in the area of Florianópolis. The experiences of suffering experienced by these workers were analyzed in the light of the theoretical framework of the Psychodynamics of Work and of artistic work literature. It was noticed that these may be related to the working conditions to which these artists are subjected to, as well as the non-recognition of their activity as work, a circumstance that to render difficult the intensification of sublimatory processes and result in the aggravation of suffering experiences.
\end{abstract}

Keywords: Suffering at Work. Artistic Work. Psychodynamics of Work. 
“Tu não fazes nada além de arte?” Uma análise psicodinâmica do trabalho artístico

\section{INTRODUÇÃO}

Em Freud (1930/2011) lê-se que a atividade humana percorre duas direções, buscar prazer e evitar o desprazer ou o sofrimento. Desse modo, para o autor, não há como eliminar o sofrimento dos sujeitos, pelo contrário, este é considerado inerente à vida humana, tendo em vista a consciência que o humano possui de sua finitude. Este autor menciona, ainda, que o sofrer ameaça os sujeitos, a partir de três direções: I) do próprio corpo, que, condenado ao declínio e à dissolução, não pode dispensar a dor e o medo como sinais de advertência; II) do mundo externo, que pode se voltar contra os humanos com forças poderosas e destruidoras; e III) das relações com outros seres humanos. No que concerne ao sofrimento originado da terceira fonte - das relações com os outros seres humanos -, Freud (1930/2011) aponta que além de inevitável, assim como aqueles que são decorrentes de origens diferentes, esse talvez seja o mais dolorosamente experimentado.

A partir da psicodinâmica do trabalho, cujo principal expoente é o francês Christophe Dejours, compreende-se que a relação de trabalho é estabelecida a partir da relação com o outro e mobiliza uma série de recursos associados à subjetividade do sujeito. Entende-se, com isso, que trabalhar pressupõe a vivência de sofrimento e de prazer. Ambas as vivências coexistentes, não definitivas e não dicotômicas - se associam à satisfação ou não de desejos inconscientes dos trabalhadores - e, assim, são vivenciadas por cada sujeito de modo singular - e são influenciadas pelo modo como o trabalho é organizado.

Ao discorrerem sobre essa temática, Dejours e Bégue (2010) apontam para a ocorrência de um agravamento do sofrimento, e patologização deste, no contexto de trabalho nas últimas décadas. Circunstância, também, associada por autores, como Moraes (2013), Merlo (2014) e Nascimento, Dellagnelo e Birochi (2018), à precarização do trabalho vivida na era da acumulação flexível e às situações dela decorrentes. Segundo relatório da Organização Mundial do Trabalho (OIT), datado de 2016, as mudanças nas relações de trabalho como o estímulo ao individualismo entre pares, altas exigências quanto à performance e produtividade dos profissionais, e, as longas jornadas de trabalho aumentam os riscos psicossociais no trabalho. Aliados a esses fatores relacionados à acumulação flexível, a OIT (2016) aponta, ainda, a ocorrência da diminuição dos postos formais de trabalho, desemprego, estabilidade financeira reduzida e as mais diversas formas de trabalhos precarizados como deletérios às subjetividades dos trabalhadores.

Um estudo desenvolvido no Brasil analisou a concessão de auxílios-doença e aposentadorias, relacionadas ou não a acidentes de trabalho, ao segurado empregado, entre os anos de 2012 e 2016. Neste, é possível observar que, no período abordado, os transtornos mentais e comportamentais foram a terceira maior causa de concessão de auxílios-doença e aposentadorias. A segunda maior causa para concessão de auxílio doença e aposentadorias por invalidez de natureza previdenciária e acidentária, ao segurado empregado, no referido período, compreende as doenças do sistema osteomuscular e do tecido conjuntivo (BRASIL, 2017). Neste grupo, pode-se encontrar patologias como àquelas compreendidas como patologias de sobrecarga (MENDES, 2007).

Um dos objetivos da análise empreendida no referido estudo foi conferir uma parcela de concretude às causas desse adoecimento, que diante da invisibilidade das cargas psíquicas do trabalho, é, na maior parte dos casos, ignorada (BRASIL, 2017). Com o intuito de corroborar este entendimento e de dar visibilidade a essas discussões, optou-se por desenvolver este artigo, que envolve reflexões acerca de vivências de sofrimento relacionadas ao contexto de trabalho. Os trabalhadores que participaram da pesquisa são artistas - quatro no total - que 
se dedicam exclusivamente a esta atividade laboral e que nela encontram seu meio de subsistência.

Um estudo desenvolvido pela Fundação Getúlio Vargas no ano de 2015 apresentou dados importantes de serem considerados a respeito do mercado de trabalho no setor cultural brasileiro. Tal estudo considerou, para fins de análise do mercado de trabalho no setor cultural, áreas tipicamente conectadas à produção artístico-cultural (música, dança, teatro, artes visuais, literatura, patrimônio cultural e circo). Nele, argumenta-se que os estabelecimentos de cultura, entre os anos de 2007 a 2013, cresceram a uma taxa superior aos demais segmentos econômicos. Ao passo que o total de estabelecimentos em todos os setores da economia, inclusive a Cultura, somavam 6.697 em 2013, o número de estabelecimentos culturais, no mesmo ano, chegou a um total de $60 \mathrm{mil}$ (FGV, 2015). No entanto, apesar de possuir um notável potencial empregatício, os estabelecimentos de cultura possuem, em média, 3,4 trabalhadores formais, em contraponto à média de 6,0 trabalhadores nos demais setores da economia. Na pesquisa apresentada pela FGV (2015), identifica-se, ainda, que os trabalhadores da cultura - incluindo-se os artistas -, possuem maior qualificação quando comparados aos demais segmentos econômicos - $81 \%$ possuem pelo menos o ensino médio completo, enquanto nos demais setores a média se aproxima de $68 \%$.

Nesse sentido, retoma-se os apontamentos de Transform (2008), que menciona que os artistas apresentam taxas elevadas de auto emprego, maior taxa das mais variadas formas de subemprego, são mais frequentemente detentores de múltiplas atividades e experimentam uma das maiores desigualdades e variabilidade de renda (TRANSFORM, 2008). Conforme exposto e reforçado por Menger (2005), pode-se observar na esfera artística formas flexíveis de trabalho - desde o mais subordinado, até o mais autônomo -, e inúmeras maneiras de exercer sua atividade - abrangendo, da pluriatividade imposta ao artista que financia sua atividade artística por intermédio do exercício de outras que lhe proporcionam subsistência.

Apesar desse contexto, raras são as pesquisas que se voltam a esses trabalhadores e, especialmente, a partir de uma perspectiva que não romantize esta atividade de trabalho, não desconsiderando e/ou mascarando aspectos reais dessa carreira profissional (MENGER, 2005; HOPE; RICHARDS, 2015). De maneira geral, as análises a respeito do trabalho na esfera artística tendem a privilegiar a obra artística enquanto criação estética em detrimento do processo de trabalho que a elaborou (MENGER, 2005).

Nessa perspectiva, acredita-se que o arcabouço teórico da psicodinâmica do trabalho pode contribuir com tal feito, uma vez que para esta abordagem, conforme explicitado, trabalhar pressupõe vivenciar tanto o prazer quanto o sofrimento. Ademais, a psicodinâmica do trabalho compreende dimensões da construção-reconstrução das relações existentes entre sujeitos-trabalhadores e a realidade concreta de trabalho. Tece críticas ao trabalho prescrito, desestabiliza o que já está posto e acaba por traduzir o trabalho a partir dos processos de subjetivação e vice-versa (MENDES, 2007).

Salienta-se que pesquisas que versem acerca do trabalho artístico, a partir da psicodinâmica do trabalho, são escassas (MONTEIRO et al., 2017). No Brasil, pode-se destacar, algumas investigações concernentes ao trabalho artístico, provenientes das áreas da psicologia e fisioterapia (LIMA, 2009; SEGNINI; LANCMAN, 2011; FERREIRA, 2011). Na área de estudos organizacionais, menciona-se duas pesquisas: Nascimento e Dellagnelo (2018) relacionam as vivências de prazer-sofrimento no trabalho artístico ao processo de mercantilização de cultura; já Nascimento, Coelho e Dellagnelo (2018) discutem e analisam as possíveis relações existentes entre o consumo cultural e a dinâmica do reconhecimento do trabalho artístico. 
“Tu não fazes nada além de arte?” Uma análise psicodinâmica do trabalho artístico

Frente à carência de estudos que, a partir de escuta, observação e análise, reflitam acerca de situações sofríveis relacionadas por artistas ao seu trabalho, justifica-se a investigação aqui proposta. Frisa-se, portanto, que o intuito desta pesquisa é refletir sobre o trabalho artístico, com foco nas vivências de sofrimento, tendo por base entrevistas semiestruturadas e observações do cotidiano de quatro artistas atuantes na grande Florianópolis/SC. Para tanto, disserta-se adiante a respeito do trabalho artístico; busca-se ainda, apresentar reflexões acerca da psicodinâmica do trabalho; posteriormente, detalha-se o processo metodológico do estudo; apresenta-se os casos de Luiz, Equilibrista, Fernando e Ricardo; discute-se sobre o sofrimento destes trabalhadores; e, finalmente, esboça-se, através dos achados do estudo, algumas considerações finais.

\section{ARTISTA ENQUANTO TRABALHADOR}

Comumente encontra-se discussões que associam o artista a um sujeito genial e excepcional, portador de um dom o qual foi - quase que divinamente - agraciado. Nesta concepção, a arte é vislumbrada como inspiração pura e a atividade artística é contemplada como forma idealmente desejável de trabalho (MENGER, 2005; TRANSFORM, 2008; HOPE; RICHARDS, 2015). Ademais, o trabalho artístico é, nesse sentido, concebido por muitos como um modelo de trabalho, por intermédio do qual, o sujeito se realiza na plenitude de sua liberdade (MENGER, 2005). Todavia, presume-se que este olhar romantizado do trabalho artístico tende a mascarar a existência de aspectos reais de uma carreira (MENGER, 2005; HOPE; RICHARDS, 2015).

Coli (2006) elucida que a concepção profissional do artista é fundamentada por uma visão idealizada da vocação. Para a autora, por trás das ideologias do lúdico, se ocultam aspectos reais de uma carreira profissional. Aspectos estes, que devem ser investigados e analisados para que se possa compreender e apontar as potenciais contradições subjacentes à dinâmica da esfera artística. Nesse sentido, analisar processos que envolvem o contexto do trabalho artístico, possibilita a percepção de como o artista é ao mesmo tempo trabalhador, mestre do desdobramento próprio, acrobata e sujeito de métier (MENGER, 2005).

Enquanto atividade de trabalho, a arte, seja ela qual for (música, literatura, teatro, dança, pintura), apresenta uma dupla face, "o lado encantador do aprofundamento e da realização de si mesmo, mas também o lado sombrio da concorrência, das diferenças espetaculares do sucesso, bem como das desigualdades que produzem essas diferenças" (MENGER, 2005, p.8). Via de regra, o trabalho artístico envolve formas de emprego precarizados, trabalhos temporários - incluindo-se aqui, projetos ou contratos de trabalho com vários clientes ao mesmo tempo -, poucos benefícios trabalhistas e uma fronteira porosa entre a vida pessoal e profissional (MENGER, 2005; TRANSFORM, 2008).

Desta feita, o trabalho artístico é caracterizado pelo retrato de um laboratório de flexibilidade, em uma economia de incertezas que propicia àqueles que nele estão inseridos, lançarem-se na hiperflexibilidade contratual (MENGER, 2005) - sinônimo do trabalho em freelance, do emprego intermitente, tempo parcial e outras formas flexíveis de trabalho (MENGER, 2005; TRANSFORM, 2008; GILL; TAYLOR, 2013).

Frisa-se que em uma esfera de trabalho cujas fronteiras entre vida pessoal e profissional são porosas - ou praticamente inexistentes -, não apenas as condições de trabalho tornam-se precárias, mas também a vida do artista (TRANSFORM, 2008). Em outras palavras, a precarização do trabalho do artista, pode implicar na precarização de si (TRANSFORM, 2008). Percebe-se, desse modo, a relevância e necessidade de se refletir acerca 
do trabalho artístico, com enfoque nas vivências de sofrimento desses trabalhadores. Ademais, acredita-se, que tais discussões podem oferecer uma ampliação dos referenciais teóricos-empíricos da psicodinâmica do trabalho (MONTEIRO et al., 2017)

\section{UM OLHAR A LUZ DA PSICODINÂMICA DO TRABALHO}

Desenvolvida inicialmente por intermédio de referenciais da psicopatologia, a psicodinâmica do trabalho incorporou conceitos advindos da Ergonomia, Psicanálise e da Psiquiatria; da Sociologia (Sociologia da Ética e Sociologia da divisão sexual do trabalho) e da Antropologia; da Filosofia (fenomenologia de Michel Henry e Escola de Frankfurt), do Direito; e, mais recentemente da Economia (DEJOURS, 2012). Os diálogos com as referidas disciplinas contribuíram para que a abordagem desenvolvida por Christophe Dejours, seu principal expoente, evoluísse para uma construção própria - que acompanhou nos últimos decênios as transformações ocorridas no mundo do trabalho, que provocaram a transição de um modelo predominantemente estável, regulado e padronizado, às formas de trabalho ditas flexíveis.

Conforme outrora menciona-se, a abordagem desenvolvida por Dejours parte de uma concepção freudiana que assume o sofrimento como inerente ao trabalho. Ou seja, o sofrimento, para a psicodinâmica do trabalho, é algo inevitável, na medida em que o trabalho impõe a prova do real. Todavia, tal qual Périlleux (2013) observa, Dejours introduz a esse entendimento, uma articulação complexa. Apesar de inevitável, o sofrimento é também vislumbrado como desejável, pois provoca uma reorganização da subjetividade. Pode-se, assim, compreender que o sofrimento que surge frente ao real do trabalho - incluindo àquele relacionado ao conflito entre os desejos da organização do trabalho e dos trabalhadores -, pode ter um destino criativo/criador ou pático (de pathos).

No sofrimento criativo, o sofrimento é mobilizado no sujeito defronte do revés, daquilo que não funcionou conforme o planejado. Ressalta-se que para a psicodinâmica do trabalho, o trabalhar implica em atividade profissional e psíquica. É ação e mobilização subjetiva frente ao real do trabalho. A mobilização subjetiva emerge, portanto, das exigências e constrangimentos da organização e, por isso, demanda um investimento do corpo, afetivo e cognitivo. Ela é apontada, ainda, como um meio para lidar com o sofrimento que implica na sua ressignificação, por intermédio de uma operação simbólica de resgate do sentido do trabalho. Destarte, a mobilização subjetiva é considerada como uma fonte de prazer no trabalho, e pode ser identificada como o processo, viabilizado pela dinâmica de reconhecimento, por intermédio do qual o trabalhador se engaja no trabalho, emprega e expande sua subjetividade, lança mão de sua inteligência prática e do coletivo de trabalho para transformar as situações causadoras de sofrimento (MENDES, 2007).

Acerca dos elementos constitutivos da mobilização subjetiva, pode-se destacar: I) a inteligência prática, inteligência do corpo ligada à ideia de astúcia, que utiliza de sua capacidade inventiva para criar novos saber-fazer, transgredindo o trabalho prescrito (DEJOURS, 2012); II) o espaço público de discussão, espaço à fala constituído pelos trabalhadores para auto expressão, autenticidade e relação de equidade entre aquele que fala e aquele que escuta (MENDES, 2007); III) a cooperação, mobilização da livre vontade de agir ou trabalhar junto, com base na confiança e solidariedade (DEJOURS, 2012; MENDES, 2007); e IV) o reconhecimento, retribuição de natureza simbólica - proferida por atores engajados na organização do trabalho -, capaz de oferecer uma gratificação ao sujeito em relação às suas expectativas, face à realização de si mesmo (DEJOURS, 2012). Este pode assumir duas formas de julgamento: o julgamento da beleza e o julgamento da utilidade. 
“Tu não fazes nada além de arte?” Uma análise psicodinâmica do trabalho artístico

Frisa-se que segundo Amaral et al. (2017), a noção de mobilização subjetiva na psicodinâmica do trabalho foi desenvolvida com inspiração no conceito freudiano de sublimação, podendo ser compreendida como uma forma de se obter satisfação sublimatória. Apesar de Sigmund Freud recorrer a tal conceito em inúmeras de suas obras, o autor não dissertou sobre ele exaustivamente. Freud (1915/2010), ao falar sobre os quatro destinos da pulsão, aponta, dentre eles, a sublimação. Este menciona que uma pulsão é sublimada quando sua força, que tem como elemento propulsor a pulsão sexual é derivada para um objetivo não sexual. A respeito da relação existente entre a atividade profissional e a sublimação, Freud (1930/2011), destaca em uma nota de rodapé que: "A atividade profissional traz particular satisfação quando é escolhida livremente, isto é, quando permite tornar úteis, através da sublimação, pendores existentes, impulsos instintuais subsistentes ou constitucionalmente reforçados". (FREUD, 1930/2011, p. 24).

Para a teoria psicanalítica, bem como para Sigmund Freud, a arte está diretamente relacionada à sublimação e à atividade artística pode ser vislumbrada como detentora de uma qualidade especial no que concerne à experimentação da sublimação (FREUD, 1920/2011). Inspirado em Freud, Dejours (2013) aborda a sublimação, relacionada ao trabalho, em três níveis: por intermédio da mobilização da inteligência prática, em que o trabalho convoca a relação do sujeito consigo; pelo reconhecimento no trabalho, que implica a relação com o outro; e por meio da contribuição do trabalho à cultura, implicando a relação do sujeito com a cultura e a civilização.

Dejours (2013), embasado em Freud, elaborou uma explicação da sublimação por intermédio do trabalho. Para o autor, enquanto processo inconsciente e maneira de o sujeito criar estratégias de enfrentamento do sofrimento e de busca pelo prazer, a sublimação constitui-se como um lugar significativo no funcionamento psíquico dos sujeitos e oferece "benefícios essenciais para a saúde mental, em termos de crescimento dos registros de sensibilidade do corpo, da identidade e do amor-próprio" (DEJOURS, 2013, p.27).

A sublimação pode ser percebida como um processo que mobiliza o sujeito a reagir aos investimentos pulsionais de uma forma mais saudável, buscando a manutenção de sua integridade psíquica, quando vem a encontrar em seu trabalho maneiras à gratificação dessas pulsões. Quando uma energia pulsional é sublimada pressupõe-se uma negociação bemsucedida entre o desejo e a realidade, não implicando em repressão, mas favorecendo a ressignificação do sofrimento. Pode-se, ainda, embasadas em Amaral et al. (2017), compreender que a partir do espaço de discussão coletivo, do reconhecimento, da cooperação e da mobilização da inteligência prática no trabalho, a satisfação de pulsões sexuais pode encontrar vias indiretas de efetivação.

Nessa perspectiva, quando a organização do trabalho não favorece canais para mobilização subjetiva ou satisfação sublimatória - que será sempre provisória -, os trabalhadores desenvolvem estratégias para não sucumbir ao adoecimento. As estratégias de defesa podem ser definidas como recursos construídos pelos trabalhadores, de maneira individual e coletiva, para minimizar a percepção do sofrimento no trabalho, através da recusa daquilo que Ihes faz sofrer (MORAES, 2013; DEJOURS, 2012). A compreensão das estratégias de defesa, na psicodinâmica do trabalho, advém da concepção psicanalítica dos mecanismos de defesa do ego (DEJOURS, 1999; DEJOURS et al., 2014).

Para Anna Freud (1946/2006, p.39), os mecanismos de defesa podem ser compreendidos como "a luta do ego contra ideias ou afetos dolorosos ou insuportáveis". Segundo a autora, todas as pessoas utilizam certo repertório de tais mecanismos. Pesquisas mais recentes demonstram que alguns usos de mecanismos de defesa podem ser mais 
saudáveis que os outros, como no caso do humor e da sublimação. Aponta-se ainda, que tais mecanismos podem variar conforme o grau de maturidade e adaptação do sujeito (CANÇADO; SANT'ANNA, 2013; VAILLANT, 1992, 2000).

Em conformidade com Dejours et al. (2014), a diferença fundamental entre os mecanismos de defesa individuais e as estratégias coletivas de defesa é que o mecanismo de defesa se encontra interiorizado, ou seja, ele persiste mesmo não havendo a presença física de outros. Já a estratégia coletiva de defesa depende de condições externas e as contribuições individuais acabam sendo coordenadas e unificadas por regras defensivas. Dejours et al. (2014, p. 128) referem que as estratégias defensivas, construídas e organizadas coletivamente, "levam à modificação, transformação, e em geral, à eufemização da percepção que os trabalhadores têm da realidade que os faz sofrer." Tal interpretação das estratégias coletivas de defesa pressupõe que vários sujeitos, experimentando de maneira singular um sofrimento único, seriam capazes de unirem seus esforços em prol da construção de uma estratégia defensiva comum.

Em princípio, as defesas tendem a refletir condutas úteis à saúde mental, no enfrentamento dos constrangimentos e contradições da organização do trabalho e manutenção da "normalidade" (DEJOURS, 1999). Em uso recorrente e prolongado, no entanto, as defesas possuem impacto negativo sobre a saúde mental dos sujeitos. Quando há um esgotamento das estratégias de defesas e uma consequente falha no enfrentamento do sofrimento, ocorre um processo de fragilização do sujeito que pode abrir caminho para a manifestação de patologias psíquicas e/ou somáticas, que caracterizam o sofrimento como patogênico (MORAES, 2013)

As patologias no trabalho, por sua vez, são formas de adoecimentos decorrentes "do contexto sócio histórico e da organização de trabalho na qual se manifesta e que afetam as relações sociais e de trabalho" (FERREIRA, 2013, p. 275). Fundamentada nas pesquisas desenvolvidas por Dejours, Mendes (2007) propõe a existência de três patologias concernentes ao trabalho: da sobrecarga, da servidão voluntária e da violência. As patologias da sobrecarga dizem respeito às lesões de hipersocialização, entre elas as Lesões por Esforços Repetitivos (LER) / Distúrbios Osteomusculares Relacionados ao Trabalho (DORT) e os problemas psicossomáticos. Já a servidão voluntária, para Dejours (2005, p.42), é considerada uma condição, entendida como "uma nova forma de escravidão moderna", face ao projeto neoliberal, sendo vinculada às necessidades de emprego e conforto na vida. As relações, nesse caso, tendem a assumir um caráter conformista e dissimulatório do sofrimento e do adoecimento, tendo em vista às exigências do contexto produtivista (FERREIRA, 2013).

A patologia da violência relaciona-se às práticas agressivas contra si mesmo, contra os outros e contra o patrimônio, em atos de vandalismo, sabotagem, assédio moral e suicídio (FERREIRA, 2013, MENDES, 2007). Ela se manifesta quando as relações subjetivas com o trabalho estão degradadas. Essa patologia ocorre de situações de estresse e da perda de sensibilidade ao próprio sofrimento e das demais pessoas (FERREIRA, 2013). Está relacionada à desestabilização da solidariedade e possui em suas bases a solidão afetiva, abandono e a desolação, relacionados ao trabalho (MENDES, 2007).

Ressalta-se que o sofrimento assume variados sentidos durante o processo de adoecimento. A dor que inicialmente pode ser sentida como banal, com o passar do tempo pode vir a limitar o movimento do corpo, forçando, dessa forma, o trabalhador a reconhecêla. Apesar de o trabalho ser constituinte da subjetividade do trabalhador, mediando a construção da identidade, através do reconhecimento; o trabalho pode também conferir ao 
“Tu não fazes nada além de arte?” Uma análise psicodinâmica do trabalho artístico

trabalhador uma condição alienante, a qual necessita ser superada em nome da saúde mental do sujeito.

\section{MÉTODO}

Realizou-se um estudo de caso instrumental-coletivo, com utilização de métodos de análise qualitativos, por compreender-se que o estudo destes casos contribui para o entendimento mais amplo da questão proposta, bem como ilustra e fornece pistas para a contestação de um discurso romantizado e harmônico do trabalho artístico como fonte inequívoca de prazer. O caráter qualitativo deu-se no reporte detalhado do material empírico representativo (não numérico), na análise dos dados provenientes e na condução do estudo no campo empírico.

Adotou-se, em termos teórico-epistemológicos, os pressupostos da psicodinâmica do trabalho. Esta requisita, ainda, uma qualificação teórico-metodológica, que seja capaz de articular a teoria social e do sujeito, a uma condução centrada na escuta do outro, além da palavra (no não dito, silenciado, oculto), para revelar o não visível e construir estratégias que permitam a aberturas de espaços de ação para ressignificação do sofrimento e um novo sentido ao trabalho (MENDES, 2007; MENDES; ARAÚJO, 2012).

Para seleção dos participantes deste estudo, três critérios foram adotados. O primeiro critério foi relacionado ao local de atuação. Ou seja, foram selecionados artistas atuantes na região da Florianópolis. O segundo foi voltado às áreas de atuação dos artistas. Haja vista a complexidade concernente à organização e definição dos setores denominados criativos e culturais, David Throsby (2001) elaborou um modelo que categoriza tais atividades em três círculos concêntricos. No cerne do modelo encontram-se as artes criativas tradicionalmente conhecidas como: artes visuais; literatura; patrimônio cultural; música; dança; artesanato; artes performáticas; e práticas que envolvem o uso de tecnologia (arte multimídia). Para FGV (2015), a economia da cultura corresponde a setores tipicamente conectados à produção artístico-cultural, a saber: música; dança; teatro; artes visuais; literatura; patrimônio cultural e circo. Nesse sentido, optou-se por buscar artistas que atuassem nas áreas apontadas por FGV (2015), pois considera-se que, em sua maioria, estas coadunam com àquelas que constam no núcleo do modelo proposto por Throsby (2001).

O terceiro critério para a seleção do grupo de artistas abrangidos por este estudo foi a satisfação de pelo menos dois dos pressupostos sugeridos por Throsby (2001). Segundo o autor, o delineamento de um grupo de artistas profissionais deve depender da aplicação de um conjunto de critérios que podem exigir que o sujeito satisfaça dois ou mais dos seguintes pressupostos: demonstrar evidência de aceitação pelos pares; possuir qualificações educacionais adequadas e/ou ter um conjunto suficiente de experiência em atividades artísticas ao invés de treinamento formal; gastar uma quantidade mínima de tempo no trabalho criativo durante um período determinado; pertencer a um organismo de certificação; e ganhar certo nível de rendimentos advindo do trabalho artístico.

A partir destes pressupostos, estudou-se os casos de quatro artistas atuantes na região da grande Florianópolis, entre os meses de setembro a dezembro de 2016. Luiz, Equilibrista, Fernando e Ricardo (pseudônimos escolhidos pelos sujeitos da pesquisa) trabalham como artistas em diferentes áreas da arte, por períodos que variam de 4 a 30 anos de experiência.

Observou-se as rotinas de trabalho, participou-se de apresentações abertas ao público e realizou-se entrevistas semiestruturadas individuais em profundidade (com duração aproximada de uma hora cada) com cada artista. Estas foram orientadas por questões amplas que possibilitaram a escuta de vivências dos participantes do estudo, relacionadas ao contexto 
de trabalho dos referidos artistas, como: conte-me sobre sua história de vida e trajetória profissional; conte-me sobre seu trabalho como artista; o que lhe dá prazer em seu trabalho? Existem situações imprevistas em seu trabalho? O que você não gosta ou lhe incomoda em seu trabalho? O que você faz para lidar/enfrentar essas situações? Em algum momento de sua trajetória como artista você já desenvolveu algum problema de saúde que acreditou estar associado a seu contexto de trabalho?

No primeiro contato com os artistas o sigilo em relação a sua identificação foi reforçado, o termo de consentimento livre e esclarecido foi explicado e assinado. Os relatos dos quatro artistas foram submetidos à análise de conteúdo categorial temática, proposta por Bardin (2016), partindo das categorias previamente definidas - vivências de sofrimento; estratégias defensivas; e patologias - e analisados à luz do arcabouço teórico da psicodinâmica do trabalho.

\section{VIVÊNCIAS E NARRATIVAS DOS ARTISTAS}

Neste tópico serão apresentados, respectivamente, os casos de Luiz, Equilibrista, Fernando e Ricardo. Destaca-se que cada pseudônimo escolhido possui um significado especial ao artista. Convém destacar a escolha de Equilibrista que, segundo ela, corresponde a uma analogia à carreira artística - inspirada na música "O bêbado e a equilibrista" -, diante da insegurança financeira, da ausência de vínculos formais de trabalho e dos benefícios por ele assegurados. Acredita-se que o pseudônimo escolhido por Equilibrista seja simbólico, por ilustrar uma condição do trabalho artístico que perpassa os discursos dos demais participantes da pesquisa, a seguir descritos.

\subsection{O Caso de Luiz}

À época da pesquisa, Luiz possuía 31 anos de idade, era graduado em publicidade e propaganda e pós-graduado em marketing estratégico e em gestão cultural pelo SENAC. Trabalhava há aproximadamente cinco anos como ator de teatro, produtor cultural e professor auxiliar de iniciação cênica e montagem teatral. Luiz mencionou que seu trabalho é permeado por circunstâncias imprevistas como a interferência do público durante as apresentações, esquecimento de fala e localização errada de cenário. Estas exigem dele uma inteligência do corpo - ligada à ideia de astúcia - que utiliza de sua capacidade inventiva para criar novos savoir-faire. Em relação ao espaço público de discussão, para Luiz, não há na região da Grande Florianópolis uma tendência a sua manutenção, assim como parece haver uma dificuldade no estabelecimento de relações de cooperação entre grupos de teatros diferentes. No entanto, Luiz referiu que em seu trabalho, tanto no centro cultural quanto no grupo de teatro, há abertura para discussões relativas ao trabalho a ser desempenhado, planejamentos a serem desenvolvidos e tomada de decisão.

As relações de cooperação no trabalho de Luiz são observadas através da admiração mútua entre os integrantes do centro cultural e do grupo de teatro e de uma intensa troca de saberes durante o processo de trabalho e na trajetória de Luiz na esfera artística. Além disso, conforme Luiz, seus pares ajudam-se mutuamente e conversam sobre a melhor maneira de executar seu trabalho. No que concerne ao reconhecimento, este tende a ocorrer, primordialmente, advindo dos pares. Nesse sentido, Luiz mencionou que o público e outros artistas de sua área que não possuem proximidade com ele nem sempre reconhecem seu trabalho. Em suas palavras: "me sinto reconhecido principalmente numa esfera mais próxima. (...) em relação ao público tem reconhecimento, mas eu diria que é muito pontual” (Luiz). 
“Tu não fazes nada além de arte?” Uma análise psicodinâmica do trabalho artístico

Para Luiz, o prazer no trabalho, além de ser vivenciado por intermédio do reconhecimento ao trabalho desenvolvido, pode ser relacionado: ao fato de exercer a profissão de livre escolha; liberdade e autonomia para realização de suas atividades de trabalho; aos momentos pré, durante e pós apresentação; processo de criação de apresentações; liberdade para criar; e, experiências exitosas diante de circunstâncias imprevistas.

A respeito das vivências de sofrimento em seu trabalho, Luiz expressou no decorrer das entrevistas, que estas estavam associadas a situações como: a não compreensão do fazer artístico enquanto trabalho; ausência de reconhecimento do público e dos pares; baixa presença de público nos eventos e/ou apresentações; pouca perspectiva de crescimento profissional; ausência de vínculos formais empregatícios e seus benefícios; e insegurança financeira. Luiz relatou que a falta de recursos financeiros para cobrir custos referentes a eventos maiores, remunerar os atores do grupo e contratar mais atores, em inúmeros momentos inviabilizou a criação de novas apresentações.

Segundo Luiz, a ausência de vínculos formais de trabalho e a instabilidade financeira seriam "os grandes problemas, os problemas gigantes" de sua profissão e contribuíam para a não compreensão do fazer artístico como trabalho por parte da sociedade, em geral. Ademais, por ter formação acadêmica em outra área, pessoas próximas ao artista, como seus pais, questionavam a sua escolha profissional: “(...) meus pais eram funcionários públicos desde cedo. Então para os dois essa questão de segurança (...) é muito importante. Vira e mexe surge esse assunto lá em casa, (...) e acaba respingando em mim" (Luiz).

Em relação à percepção de mecanismos de defesas do ego, identificou-se o humor e a racionalização como estratégias recorrentes e presentes no conteúdo expresso verbalmente pelo artista. $\mathrm{O}$ uso do humor marca a fala de Luiz ao referir-se à sua reação (e dos colegas) à baixa presença de público nos eventos/apresentações: Nas palavras de Luiz: "(...) a gente faz graça, assim: "chegou um, agora dois." Fazer o quê? Vou chorar?". A racionalização pode ser vislumbrada quando o artista utiliza argumentos lógicos para explicar escolhas ou adaptações por questões financeiras:

Não precisa eliminar outro trabalho que envolve fazer artístico, mas que tá relacionado com o comercial. Acho que se for para produzir alguma coisa e vender, prefiro produzir algo artístico (...). Eu posso pegar um assunto que eu acho bacana e que vai ser construtivo para as crianças (Luiz).

Não obstante aos aspectos sofríveis decorrentes do trabalho, o artista não relacionou patologias ao exercício artístico. Todavia, foram relatados alguns sintomas que lhe causavam desconforto: “(...) tem momentos difíceis, momentos de estresse (...). (...) tem também, momentos pontuais de dúvidas, até de tristeza, de angústia, de não saber como eu vou sair dessa" (Luiz). Apesar de destacar essas vivências sofríveis, relacionadas ao seu trabalho enquanto artista, segundo Luiz, os momentos prazerosos, por ele experimentados, são mais frequentes. $\mathrm{O}$ artista foi enfático: “(...). Essa liberdade de expressão me faz gostar muito de trabalhar aqui. (...). (...) esse é o emprego que eu quero ter, eu tô no emprego dos meus sonhos (Luiz)".

Pode-se, ainda, ressaltar a relevância atribuída ao processo de criação artística na ressignificação de situações sofríveis decorrentes do contexto de trabalho artístico. Luiz relata que, para superar as instabilidades financeiras, seu grupo de teatro desenvolve algumas apresentações com maior aceitação comercial, mas busca outros espaços para criar com 
maior liberdade - diminuindo o sentimento desconfortável e incômodo resultante da formatação.

\subsection{O Caso de Equilibrista}

À época da pesquisa, Equilibrista possuía 25 anos de idade, era coreógrafa, bailarina, professora de dança e graduanda em arquitetura. Tinha aproximadamente 20 anos de participações em festivais e outros eventos de dança e atuava há cinco anos como professora de dança. Equilibrista discorreu que frequentemente ocorrem imprevistos em apresentações e participações em eventos de dança. Tais situações, segundo a artista, tendem a ser relacionados a fatos de ordem técnica (música, iluminação, cenário) ou à execução das coreografias. Estas exigem dela o uso de sua capacidade inventiva para criar a melhor solução possível num espaço temporal limitado.

Equilibrista relatou que na escola de dança em que trabalha, diferente dos demais locais de trabalho, há um espaço de discussão em que os professores de dança se reúnem com certa frequência para discutirem em conjunto com a direção da escola, questões relativas ao seu trabalho e a eventos a serem realizados. As relações de cooperação no trabalho de Equilibrista ocorrem de maneira variada. Enquanto dançarina e dirigente de uma companhia de danças urbanas, percebe-se que a cooperação se faz presente, sendo observada através da admiração mútua entre dirigentes e integrantes dos grupos de dança. Todavia, como professora de dança, ressalta-se que as relações de cooperação ocorrem de maneira limitada.

No que concerne ao reconhecimento pelo trabalho desenvolvido, Equilibrista mencionou acreditar que a presença marcante de eventos de dança, dificulte a existência do reconhecimento do trabalho desenvolvido pelo outro. Equilibrista discorreu que, de maneira geral, o reconhecimento do trabalho por ela desenvolvido, proveniente de outros profissionais da dança, é relacionado a professores de outros estilos de dança, da escola de dança que ela trabalha, e a artistas que conhecem sua evolução enquanto dançarina: "Sempre se tem um pouco de resistência, naquela coisa de uma competitividade, mas de modo geral, eu acho que tem um reconhecimento bacana nos outros professores da escola de dança. (...). O reconhecimento que temos com outros artistas é muito vinculado aos artistas que conhecem o nosso processo dentro da dança" (Equilibrista). Segundo Equilibrista, além de haver, de maneira geral, um reconhecimento por seu trabalho desenvolvido enquanto professora de dança pelas organizações em que ela trabalha, a artista, também destacou a ocorrência do reconhecimento proveniente do público que assiste às apresentações: "o retorno das pessoas que assistem, costuma ser positivo" (Equilibrista).

Para Equilibrista, o prazer no trabalho, além de ser vivenciado por intermédio do reconhecimento ao trabalho desenvolvido, pode ser relacionado: ao fato de exercer a profissão de livre escolha; aos momentos durante e pós apresentação; possibilidade de ensinar, aprender com seus alunos e acompanhar a evolução dos mesmos na dança; processo de criação; liberdade para criar; e experiências exitosas diante de circunstâncias imprevistas.

Equilibrista expressou no decorrer das entrevistas que as vivências de sofrimento em seu trabalho estiveram associadas: à não compreensão do fazer artístico como um trabalho, por parte da sociedade em geral; ao pouco reconhecimento do trabalho desenvolvido proveniente dos pares; ausência de vínculos formais de trabalho e benefícios assegurados; inseguranças financeiras; ritmo de trabalho intenso; restrição na liberdade de criação e expressão - incluindo-se: condução das aulas de dança; escolha de músicas; e criação de coreografias, figurinos e cenário.

No que tange à não compreensão do fazer artístico como um trabalho por parte da sociedade em geral, a artista relata que o fato de trabalhar com algo que lhe dá prazer e que 
“Tu não fazes nada além de arte?” Uma análise psicodinâmica do trabalho artístico

Ihe faz bem, é, inúmeras vezes, percebido de uma maneira depreciativa por várias pessoas que tendem a associar trabalho ao esforço desprovido de prazer. O sofrimento permeia o relato da artista, também, quando fala do trabalho associado à instabilidade financeira próprio da ausência de um vínculo formal de trabalho e dos benefícios dele decorrentes. Este contexto leva Equilibrista a trabalhar simultaneamente em projetos múltiplos e com diferentes parceiros/clientes, o que a faz intensificar o ritmo de trabalho, gerando desgaste físico e psíquico. Conforme a artista:

Gostaria desse tipo de coisa, poder pagar um plano de saúde, poder pensar que eu posso ter uma aposentadoria, que algum dia na vida ainda vou ter esses direitos que estão muito vinculados a garantia de uma qualidade de vida, uma vida que um humano merece e que muitas vezes a gente não sabe se vai ter (Equilibrista).

Equilibrista relatou, ainda, que o reconhecimento de seu trabalho por seus pares é dificultado pela presença marcante de competições entre dançarinos e grupos de dança e pela padronização das avaliações em festivais. Diante destes aspectos, identificou-se como um mecanismo de defesa utilizado pela dançarina a racionalização. Esta pode ser vislumbrada no conteúdo da fala de Equilibrista, quando a artista argumentou (também para autoconvencimento) que as condições instáveis inerentes ao trabalho "fazem parte do processo".

As patologias no trabalho da dançarina estão associadas ao ritmo de trabalho intenso, que tende a aumentar em períodos de apresentações/eventos e que, além de provocarem desgaste físico e psíquico, causam frequentemente lesões musculares. A despeito disso, destaca-se a relevância atribuída por Equilibrista à possibilidade de criação artística e ao fato de trabalhar com dança na ressignificação de vivências de sofrimento e de experimentação de prazer: "ninguém e nenhum trabalho é só prazer," mas "os momentos de prazer acabam sendo maiores que os momentos de desprazer".

Segundo a artista, as circunstâncias anteriormente descritas - criação e trabalho na dança - a auxiliam a lidar com vivências sofríveis de seu cotidiano de trabalho na dança: "Eu trabalho na dança exatamente pelo prazer. (...). Tem a insegurança financeira, às vezes não tem reconhecimento (...). Mas a dança me faz perceber eu mesma (...) e faz eu ir ressignificando isso" (Equilibrista).

\subsection{O Caso de Fernando}

À época da pesquisa, Fernando possuía 29 anos de idade, era músico associado à ordem dos músicos do Brasil e luthier. Com aproximadamente 20 anos de experiência na música e 10 anos trabalhando como artista, Fernando expressou no decorrer das entrevistas que seu trabalho é marcado pela existência de situações imprevistas, em que o artista precisa ter experiência para que consiga agir rápido e para que a situação seja contornada: "tem que dar um jeito e rápido, não tem muito tempo para pensar. (....) Já aconteceu de (...) o pessoal beber e subir em cima do palco e pisar em instrumento, derrubar bebida no instrumento. (...), mas tem que tá preparado para tudo (...)" (Fernando).

O trabalho de Fernando é marcado pela existência de vários clientes e serviços oferecidos de maneira concomitante. Ressalta-se que esta circunstância tende a influenciar na existência de um espaço de discussão, na manutenção deste espaço e das relações de cooperação no trabalho. Em seu trabalho enquanto músico, há maior espaço de discussão e cooperação do que em outros trabalhos por ele realizados. Nos espaços em que se faz presente, a cooperação pode ser observada através da admiração mútua entre os 
profissionais e de existência de uma intensa troca de saberes durante o processo de trabalho. No trabalho desenvolvido por Fernando, além da troca mútua de saberes, os artistas ajudam uns aos outros e conversam sobre a melhor maneira de executar seu trabalho. No que tange ao reconhecimento de seu trabalho, Fernando afirmou que, no seu caso, tal retribuição simbólica pode ser proveniente do público, de outros artistas, de contratantes e/ou de patrocinadores. Todavia, o artista referiu ser mais reconhecido entre outros músicos do que pelo público. A respeito de tal situação, Fernando referiu o seguinte: "ele é reconhecido pela parte que é para ser reconhecido".

Para Fernando, o prazer no trabalho, além de ser vivenciado por intermédio do reconhecimento ao trabalho desenvolvido, pode ser relacionado: ao fato de exercer a profissão de livre escolha; ao processo de criação; liberdade para criar - incluindo-se: o uso da identidade musical; desenvolvimento de música autoral; e escolhas das músicas a serem tocadas. -; e experiências exitosas diante de circunstâncias imprevistas.

Fernando relatou vivências de sofrimento associadas à: não compreensão do fazer artístico como um trabalho; ausência de vínculos formais de trabalho; pouca presença de benefícios trabalhistas; insegurança financeira; pouco reconhecimento do público; ritmo de trabalho intenso; não fronteira entre vida pessoal e profissional; necessidade de adaptação do exercício artístico às oportunidades de trabalho e desejo do contratante; e, restrição da liberdade - no uso da identidade musical; na composição autoral; e nas escolhas das músicas a serem tocadas.

Fernando evidenciou também a falta de reconhecimento por parte da sociedade em geral da música enquanto trabalho: "às vezes chega em algum lugar e precisa fazer um cadastro. Profissão? Músico. Tá, mas tu só fazes isso? A pergunta clássica". Fernando relatou que, embora sofra por causa da falta de reconhecimento externo pelo seu trabalho, a resistência de sua família em aceitar, no início da carreira, sua escolha profissional o afetou emocionalmente de forma mais profunda. Foi, segundo Fernando, "angustiante". A ausência de vínculos formais e benefícios trabalhistas e a insegurança financeira dificultaram, para Fernando, a assimilação de seu fazer enquanto trabalho.

As restrições sofridas no exercício artístico por Fernando ficam evidentes ao relatar que o gênero musical em que possui maior volume de trabalho, o sertanejo, não é o de sua preferência, mas decorre da necessidade de adaptação às exigências do mercado. Fernando descreveu, ainda, como fonte de sofrimento, o ritmo intenso de trabalho: “(...) meu ritmo é muito intenso. Às vezes eu fico dias fora de casa, muitas noites eu não durmo em casa. Eu acho isso horrível. (...) final de semana não existe, na verdade é no fim de semana que a gente mais trabalha" (Fernando). O ritmo, somado ao contexto de trabalho marcado por instabilidade e informalidade contratual, flexibilidade de horários, provocam o alastramento da vida profissional à esfera pessoal.

Diante deste contexto, identificou-se como principais defesas utilizadas por Fernando a racionalização e a somatização. A racionalização é utilizada por Fernando para explicar a aceitação de situações contrárias à sua preferência ou valores pessoais. O músico argumentou que aceitar tocar estilo musical que não lhe agrada, é fator de amadurecimento profissional e necessidade de adaptação às exigências do mercado: "Eu sou um prestador de serviço. A minha responsabilidade é isso, estudar e cumprir aquilo pra que me contrataram".

Fernando descreveu que, frequentemente, apresentava sentimentos depressivos, azia e dor no estômago: sintomas que podem ser associados à somatização, além de tendinite, uma patologia da sobrecarga. Embora a somatização e patologias da sobrecarga se façam presentes na fala de Fernando, também possível perceber relevância atribuída à criação 
“Tu não fazes nada além de arte?” Uma análise psicodinâmica do trabalho artístico

artística na ressignificação de algumas situações sofríveis decorrentes de seu contexto de trabalho como músico: "É uma terapia. Eu uso para desintoxicar, às vezes, a parte que eu tô agitado, turnê, estrada e tal. É uma terapia. Me ajuda a aliviar o stress" (Fernando).

\subsection{O Caso de Ricardo}

Ricardo, artista plástico, músico e carnavalesco, na época da pesquisa possuía 49 anos de idade e mais de 30 de experiências de trabalho como artista. Ricardo, no decorrer das entrevistas, mencionou que sua atividade laboral é marcada pela presença de situações imprevistas como materiais de trabalho que estragam no momento do uso e esculturas que apresentam fissuras. Casos que requisitam ao artista experiência e habilidade para que se consiga agir rápido e para que a situação seja contornada. No que tange ao espaço público de discussão e a cooperação, vale destacar que enquanto artista plástico, Ricardo, na maior parte das vezes, trabalha sozinho. Todavia, em seu trabalho enquanto músico e integrante de uma banda teatral, tais elementos, para o sujeito, se fazem presentes, ainda que o primeiro ocorra de maneira limitada.

A cooperação entre os integrantes da banda pôde ser observada através da admiração mútua, de uma intensa troca de saberes durante o processo de trabalho e disposição em auxiliarem-se uns aos outros para que o trabalho conjunto seja desenvolvido do melhor modo possível. A respeito do reconhecimento de seu trabalho, Ricardo considera-se reconhecido pelo público e colegas de profissão. Para Ricardo, o prazer no trabalho, além de ser vivenciado por intermédio do reconhecimento ao trabalho desenvolvido, pode ser relacionado: ao fato de exercer a profissão de livre escolha; ao processo de criação; liberdade para criar incluindo-se: obras de arte; espetáculos; e músicas autorais. -; e experiências exitosas diante de circunstâncias imprevistas.

Ricardo relatou, ainda, que as vivências de sofrimento relacionadas ao seu trabalho podem ser associadas à: não compreensão do fazer artístico como um trabalho, por parte da sociedade, em geral; ausência de vínculos formais de trabalho e dos benefícios trabalhistas a eles associados; insegurança financeira; necessidade de adaptação às oportunidades e desejos do contratante/cliente; ritmo de trabalho intenso; cobrança por desempenho; restrição da liberdade - na criação de obras de arte; desenvolvimento de espetáculos; e composições musicais.

De acordo com Ricardo, a atividade artística, tende a não ser percebida como um trabalho, principalmente por pessoas que possuem um vínculo empregatício formal. $\mathrm{O}$ artista é, frequentemente, questionado: "Tu não fazes nada além de arte?"; "Tu pintas quadro? Mas tu não trabalhas?" Para o artista, há uma ideia que associa o trabalho artístico ao lazer, ou hobby, não havendo, de maneira geral, a compreensão do fazer artístico como trabalho. Sobreviver financeiramente trabalhando exclusivamente com arte é encarado por Ricardo como o maior desafio da vida do artista e impõe limitações à criação que geram sofrimento: "incômodo, angústia". Embora a ausência de vínculo formal tenha consequências negativas, Ricardo diz preferir trabalhar em várias áreas da esfera artística, do que manter um vínculo formal e horário de trabalho definidos.

Identificou-se, no relato do artista, estratégias defensivas, como: a racionalização; hiperatividade no trabalho ou trabalho compulsivo; e a somatização. A racionalização pode ser vislumbrada no conteúdo da fala de Ricardo, quando o artista fornece uma explicação racional para o fato de ainda não ter conseguido subsistir exclusivamente da música: A música é um mundo muito difícil. (...). Não deu, mas depois eu fui entender que o cenário é outro, tens que ser diferenciado, (...) hoje né, o que tá diferenciado, na moda é o lixo do lixo 
(Ricardo). Ricardo referiu, inclusive, que inúmeras vezes intensifica seu ritmo de trabalho, não realizando pausas entre as atividades desempenhadas. Isto sugere o uso de algumas dinâmicas que se aproximam da hiperatividade no trabalho, ou trabalho compulsivo, como uma defesa que evita o contato com dimensões angustiantes no trabalho, mantendo o trabalhador ocupado (DEJOURS, 2004; MARZANO, 2004).

Frente à carga intensiva de trabalho, associada à forte cobrança por desempenho, tanto pessoal quanto proveniente de seus contratantes e/ou clientes, e prazos curtos para entrega de obras, Ricardo referiu apresentar insônia, stress e problemas gastrointestinais. Diante do exposto, observa-se a presença da somatização enquanto defesa que traduz em sintomas físicos, conflitos intrapsíquicos:

Trabalho com data é muito complicado, é uma coisa que crucifica. Fica sem dormir porque tá preocupado, fica sem dormir porque quer entregar o trabalho. Dorme duas horas. (...) no carnaval o trabalho é grande, e a consagração é um dia. Pode ser consagrado, como pode ser crucificado (Ricardo).

Além dos sintomas anteriormente apresentados, Ricardo referiu que o uso de materiais como tintas e vernizes, por vezes, acaba ocasionando tosse, irritação na garganta e irritações na pele. Não obstante, Ricardo destacou o papel da criação artística na ressignificação de vivências sofríveis associadas a seu contexto de trabalho: "a criação é o que mais me motiva, senão eu não trabalharia com arte".

\section{TRABALHO ARTÍSTICO E VIVÊNCIAS DE SOFRIMENTO: UM ESFORÇO ANALÍTICO DE DESROMANTIZAÇÃO DO REAL DO TRABALHO}

No arcabouço teórico da psicodinâmica do trabalho discute-se que o real se manifesta de modo intempestivo como furo ou ruptura do prescrito. Com isso, evidencia-se que as experiências ou vivências dos trabalhadores ultrapassam as prescrições, extrapolam aspectos físicos e envolvem dimensões subjetivas e invisíveis, ou ocultas, do contexto de trabalho. Desse modo, ao se considerar que o real coloca em xeque a aparente harmonia dos ordenamentos simbólicos do prescrito, não se é possível discutir acerca de contextos de trabalho e atentar-se apenas às suas dimensões materiais e objetivas.

Ao se considerar que os sujeitos experimentam tanto vivências de prazer quanto de sofrimento relacionadas ao seu contexto de trabalho, é possibilitado que se atente para o real que envolve os contextos de trabalho de modo menos ingênuo ou romântico (SEGNINI; LANCMAN, 2011; FERREIRA, 2011). No que concerne ao trabalho artístico, salienta-se que este foi relacionado, a partir do conteúdo verbal expresso pelos artistas participantes deste estudo e das observações realizadas, a vivências sofríveis decorrentes de situações, como: não compreensão do fazer artístico como um trabalho, por parte da sociedade, em geral; ausência de vínculos formais de trabalho; inexistência ou pouca presença de benefícios trabalhistas assegurados pela CLT; inseguranças financeiras; ausência de reconhecimento da beleza do trabalho desenvolvido; ritmo de trabalho intenso; e liberdade para criar limitada.

Entende-se que a não compreensão da atividade artística enquanto trabalho, além de provocar a vivência de sofrimento nos sujeitos, pode também ter um efeito deletério na saúde psíquica do trabalhador, bem como na construção da sua identidade. Não compreender a atividade artística enquanto trabalho é não reconhecer o artista enquanto trabalhador e tal relação não permanece neutra no que concerne à saúde mental de tais profissionais. Para Dejours (1999, 2012), o reconhecimento enquanto simbólico e possibilitador da transformação do sofrimento em prazer trata-se da identidade que deseja realizar-se. 
“Tu não fazes nada além de arte?” Uma análise psicodinâmica do trabalho artístico

Contudo, destaca-se que esta não compreensão do fazer artístico como trabalho pode estar associada a diferentes questões e pode ser correlacionada a outras fontes de sofrimento no trabalho artístico, como: ausência de vínculos formais de trabalho; inexistência ou pouca presença de benefícios trabalhistas assegurados pela CLT; inseguranças financeiras; ausência de reconhecimento da beleza do trabalho desenvolvido. Nas sociedades ocidentais capitalistas, o pensamento cristão exerce influência naquilo que se concebe por trabalho. Do tripalium, momento de punição, mal necessário, se tem no fim da idade média, reforçado pela moral protestante, a associação do trabalho a algo dignificante, a um propósito de vida. Trabalho este, executado mediante recompensas financeiras e relacionado, à época, a profissões regulares, demarcadas, sistemáticas e metódicas (WEBER, 1904/2013). Profissões que ainda hoje, ao envolverem o exercício de uma atividade profissional mediante contrato formal sustentam-se como formas de inserção e reconhecimento social (DEJOURS, 2004).

Frente a um cenário econômico e político instável, e do avanço de um discurso neoliberal, promove-se e legitima-se formas ditas flexíveis de trabalho, em que a flexibilidade aparece como sinônimo de precariedade e o trabalhador é conduzido a sentir-se responsável pelos resultados de seu trabalho e carreira. Aqui se vê surgir a ampla disseminação do trabalho autônomo e dos contratos temporários (não obstante à precariedade de suas condições) como libertários - portanto, desejáveis - e do empreendedor como um modelo ideal de sujeito/trabalhador (DARDOT; LAVAL, 2016). A promoção e busca pela legitimação do discurso do empreendedor - e deste enquanto trabalhador - parece contraditória quando se pensa na não compreensão da atividade artística enquanto trabalho e no não reconhecimento do artista como trabalhador. Menciona-se isto, tendo em vista as aproximações que envolvem suas condições de trabalho - como, trabalho autônomo, intermitente e variabilidade de renda/inseguranças financeiras.

Isto posto, retoma-se a argumentação de Nascimento et al. (2018) acerca da predominância de pelo menos dois elementos, inter-relacionados, que contribuem para uma não compreensão do trabalho artístico nas sociedades de consumo: a) a ascensão de um modo limitado de julgamento da utilidade, que dificulta o reconhecimento social do fazer artístico enquanto trabalho; e b) a inibição do julgamento da beleza provocada pelo ethos competitivo do modo de produção capitalista. Reforça-se o entendimento de que a noção restrita do julgamento da utilidade tem como consequência o não reconhecimento social do fazer artístico enquanto trabalho. Ressalta-se que o questionamento da utilidade técnica, econômica e social da atividade artística nas sociedades atuais parece - especialmente quando se pensa na legitimação social que o discurso do empreendedorismo tem obtido superar o fato de o trabalho artístico envolver uma atividade de trabalho executado mediante recompensa financeira por vínculo empregatício, preferencialmente formal.

A restrição da liberdade para criar, outro aspecto apontado como fonte de sofrimento no trabalho artístico é percebido pelos artistas de forma singular. Entre os sujeitos da pesquisa, Ricardo e Fernando, que trabalham exclusivamente na esfera artística há mais tempo que Equilibrista e Luiz, demonstraram possuir menor liberdade para criar. Retoma-se o argumento de Dejours (1999) quando o autor afirma que o artista não pode escapar das relações de mercado. Ao se estabelecer relações mercantis entre o artista, o público e/ou o patrocinador, corre-se o risco de a arte passar a ser percebida como um meio de produção e a criação artística como um objeto de consumo, possibilitando que os desejos ou necessidades do patrocinador e do público predominem sobre os desejos ou necessidades dos artistas. Desse modo, pode ocorrer a instalação do sofrimento, pois não se vê mais na arte uma 
atividade destinada a harmonizar, em primeiro lugar, os desejos não gratificados do artista e em segundo lugar, os do público.

Frente à vivência de sofrimento, há que se destacar o papel das defesas que entram em ação para possibilitar ao ego o estabelecimento de soluções, buscando que alguns componentes de conteúdos mentais não desejados, cheguem ao consciente de maneira minimizada ou disfarçada. As estratégias de defesa podem ser tanto de ordem individual quanto coletivas (DEJOURS, 1992, 2012) e, de modo geral, não auxiliam na subversão do sofrimento em prazer. Ao impedir que o trabalhador não pense naquilo que lhe faz sofrer no trabalho, as estratégias de defesa acabam inibindo a transformação das fontes de tal sofrimento (DEJOURS et al., 2014). Percebeu-se o uso, em todos os casos, de pelo menos uma estratégia de defesa individual. Entretanto, existem particularidades a serem ressaltadas a respeito de cada caso.

As falas de Fernando e Ricardo indicam o uso da somatização. Enquanto estratégia de defesa individual, a somatização implica na tradução, de maneira desproporcional, em sintomas físicos, conflitos intrapsíquicos (VAILLANT, 1992, 2000; CANÇADO; SANT'ANNA, 2013). No caso de Fernando, a somatização pode se fazer presente em sua fala, quando o artista relata que em momentos conturbados, como a falta de apoio no início de sua carreira, frequentemente apresentava sintomas depressivos, azia e dor no estômago. Em relação a Ricardo, pode-se pensar na somatização, quando o artista discorre que frequentemente apresenta insônia, stress e problemas gastrointestinais.

A partir do conteúdo transmitido por Ricardo, em que este relata que inúmeras vezes intensifica seu ritmo de trabalho, não realizando pausas entre as atividades desempenhadas, é possível pensar também no uso da hiperatividade no trabalho como estratégia de defesa individual. A hiperatividade ou o trabalho compulsivo, de acordo com Dejours (2004) e Marzano (2004), podem ser consideradas defesas contra o sofrimento no trabalho que permitem ao trabalhador manter-se ocupado sem entrar em contato com dimensões que lhe angustiam. Alguns trabalhadores possuem sua identidade atrelada ao trabalho, de maneira que parar de trabalhar pode proporcionar uma angústia demasiadamente grande, impossibilitando o desligamento de sua atividade.

No conteúdo trazido à luz por Luiz, além da racionalização, pode-se pensar no uso do humor. O humor diz respeito a expressar experiências dolorosas de maneira espontânea e sem aparente incômodo, para si e para quem está ao redor (VAILLANT, 1992, 2000; CANÇADO; SANT'ANNA, 2013). Assim como evidenciado no estudo desenvolvido por Lima (2009), o uso do humor se faz presente na fala de Luiz, como uma estratégia para lidar com a adversidade. Luiz referiu que diante da pouca presença de público, ele e seus colegas de trabalho costumam rir da situação. Apesar do relato de estresse, tristeza e angústia associados à instabilidade financeira, Luiz, assim como Ricardo, não referiu o desenvolvimento de patologias relacionadas. Já Equilibrista atribui a um ritmo de trabalho intenso, além de desgaste físico e psíquico, o surgimento recorrente de lesões musculares. Além dos sintomas relacionados à somatização, Fernando, referiu possuir tendinite. As patologias apresentadas por Equilibrista e Fernando relacionam-se à sobrecarga de trabalho (MENDES, 2007).

Além do destino pático do sofrimento vivenciado no cotidiano de trabalho de Luiz, Equilibrista, Fernando e Ricardo, observa-se o criativo. Conforme mencionado, no sofrimento criativo há uma mobilização subjetiva, uma forma de satisfação sublimatória que possibilita a subversão do sofrimento em prazer. Em Dejours (2013), se lê que essa mobilização subjetiva pode ser potencializada pela inteligência prática, espaço à fala, cooperação e reconhecimento. A vivência de situações imprevistas também é apontada como algo constante no cotidiano do 
“Tu não fazes nada além de arte?” Uma análise psicodinâmica do trabalho artístico

artista, o que demanda uma necessidade frequente de inventividade. Observa-se também, que o trabalho do artista é norteado por um saber prático, construído a partir de trocas com os pares e com o tempo de trabalho (SEGNINI; LANCMAN, 2011; FERREIRA, 2011), visto que diante de situações complexas, variadas e imprevistas, nem sempre as prescrições e o conhecimento técnico-científico são suficientes (COSTA, 2013).

Em relação à existência de um espaço público de discussão e deliberação, com base no conteúdo verbal expresso pelos artistas, pôde-se observar a existência de alguns espaços para discussões pertinentes a maneira de executar as atividades de trabalho. Contudo, não foi possível perceber a existência de um espaço onde o artista, enquanto trabalhador, possa repensar seu trabalho ao falar sobre ele, interpretá-lo e modificá-lo na busca da ressignificação de situações sofríveis. Este fato, que pode ser deletério à saúde desses trabalhadores, pois este espaço possibilita a convivência, resgata os vínculos afetivos, a solidariedade e a cooperação entre eles (MERLO et al., 2013).

Com exceção do caso de Luiz, não foi possível perceber a existência de relações de cooperação em todos os trabalhos desempenhados pelos artistas. Conforme observado, o artista de teatro e seus pares tentam manter, tanto no centro cultural quanto no grupo de teatro, práticas organizacionais associadas a um estilo de gestão mais horizontalizado, como: tomada de decisão, planejamento e divisão de tarefas realizados coletivamente. Observou-se ainda, que ante à busca por destaque na esfera artística, a "construção de um nome forte", a concorrência por premiações e editais de incentivo a arte e cultura, parece haver predomínio de um comportamento individualista, principalmente, entre membros de diferentes grupos ou bandas.

Esse individualismo que dificulta as relações de cooperação entre artistas, em especial, de grupos e/ou bandas distintos, influencia negativamente na ocorrência do reconhecimento do trabalho artístico, por meio da inibição do julgamento da beleza do trabalho desenvolvido (SEGNINI; LANCMAN, 2011; NASCIMENTO et al., 2018) Destaca-se que o reconhecimento é apontado pelos participantes como forma de vivenciar prazer no trabalho, em especial, quando este é proferido pelos pares. Assim como a mobilização subjetiva pode ser vivenciada como uma espécie de satisfação sublimatória e atuar na ressignificação do sofrimento (DEJOURS, 2013), percebeu-se algumas outras situações em que acredita-se ser possível falar em sublimação e de subversão do sofrimento em prazer: trabalhar na profissão de livre escolha (FREUD, 1930/ 2011) e criar livremente (FREUD, 1920/ 2011).

Em resumo, considerou-se presentes no cotidiano de trabalho de Luiz, Equilibrista, Fernando e Ricardo, tanto o sofrimento criativo quanto o patogênico. Contudo, Fernando e Ricardo, artistas que mantêm suas famílias com renda obtida exclusivamente da arte e que trabalham na esfera artística por mais tempo que Luiz e Equilibrista, apresentam quadros em que o sofrimento patogênico tende a prevalecer ao criativo, dadas as estratégias de defesa utilizadas e os sintomas e patologias por eles associados ao trabalho. Apesar disso, reafirmase que ambos os artistas identificam no trabalho artístico a possibilidade de ressignificação de inúmeras situações sofríveis.

\section{CONSIDERAÇÕES FINAIS}

Buscou-se, neste trabalho, refletir sobre o trabalho artístico, com foco nas vivências de sofrimento. Para tal feito, recorreu-se à psicodinâmica do trabalho e a literaturas concernentes ao trabalho artístico. Participaram desta investigação quatro artistas atuantes na região da grande Florianópolis, com diferentes tempos de atuação na esfera artística. Identificou-se a partir da observação do cotidiano de trabalho e das narrativas dos sujeitos 
que os fatores que influenciam tais vivências relacionam-se aos critérios de validação, legitimação, reconhecimento e absorção de atividades por padrões de utilidade e rentabilidade inerentes ao ethos capitalista, que fogem ao fazer artístico produtor de sentido, de difícil mensuração de valor, que guarda, portanto, peculiaridades estranhas, ou até contrastantes, à lógica produtiva ocidental-capitalista.

Não absorvidos pelo mercado de trabalho por vínculos empregatícios formais, por não se enquadrarem na produção de utilidades e bens de fácil comercialização, e não reconhecidos enquanto trabalhadores, os artistas enfrentam situações, como: instabilidade financeira, mediante condições de trabalho adversas; contratos hiperflexíveis, precários e informais, que restringem a liberdade de criação; e, assumem um ritmo intenso de trabalho ao se envolverem em projetos múltiplos com diferentes clientes. Tais situações lhes causam desgastes físicos e psíquicos que podem a ser intensificados com o tempo de atuação na esfera artística e com a idade dos sujeitos.

Apesar de a arte, enquanto trabalho ser considerada uma atividade com alto potencial sublimatório por Freud (1920/2011) e Dejours (2013), observou-se, neste estudo, que quando o artista, diante da necessidade de retorno financeiro, subjuga sua criação aos ditames do mercado, ocorre uma maior dificuldade para a intensificação de processos de sublimação e também facilita o agravamento das vivências de sofrimento, circunstância que pode provocar a instalação de desestabilização psíquica e adoecimento. No entanto, estes trabalhadores, ainda que não reconhecidos como tais, encontram no exercício artístico a possibilidade de subversão de inúmeras experiências sofríveis influenciadas pelo próprio exercício da arte enquanto trabalho. Diante desse contexto, adverte-se acerca da nociva romantização da atividade de trabalho a que esta pesquisa se destinou a aludir. Tal romantização, a medida em que desconsidera contextos de trabalho precarizados e situações sofríveis, pode atuar na legitimação de tais condições de trabalho, bem como influenciar no não reconhecimento do artista enquanto trabalhador.

Conforme explicitado na introdução, verificou-se que existem poucos estudos relacionados às vivências de prazer e sofrimento no trabalho artístico, nas diversas áreas do conhecimento, em especial, na área dos estudos organizacionais. Assim, sugere-se que estudos futuros utilizem do arcabouço teórico da psicodinâmica para efetuar investigações relacionadas ao trabalho artístico, e que quando possível envolvam coletivos de trabalho. Como limitações da presente investigação, pode-se indicar um aspecto pertinente a estratégia adotada no método. Devido à agenda repleta de compromissos dos artistas, não foi possível realizar sessões coletivas, optou-se assim por entrevistas individuais. Apesar de terem emergido nas referidas entrevistas, conteúdos significativos para esta investigação, acreditase que as sessões coletivas poderiam favorecer o reconhecimento de contradições, bem como a construção de um discurso coletivo.

\section{REFERÊNCIAS}

AMARAL, G. A. MENDES, A. M. B.; CHATELARD, D. S. CARVALHO, I. S. O lugar do conceito de sublimação na psicodinâmica do trabalho. Revista Polis e Psique, Porto Alegre, v. 7, n. 3, p. 200-223, 2017. DOI:10.22456/2238-152X.66740.

BARDIN, L. Análise de conteúdo. São Paulo: Edições 70, 2016. 
“Tu não fazes nada além de arte?” Uma análise psicodinâmica do trabalho artístico

BRASIL. Ministério da Fazenda. 10 Boletim quadrimestral sobre benefícios por incapacidade. Adoecimento mental e trabalho: a concessão de benefícios por incapacidade relacionados a transtornos mentais e comportamentais entre 2012 e 2016. Brasília: Ministério da Fazenda, 2017. Disponível em: <http://sa.previdencia.gov.br/site/2017/04/1\%C2\%BA-boletim-quadrimestral.pdf>. Acesso em: 13 de novembro de 2019.

CANÇADO, V. L; SANT'ANNA, A. S. Mecanismos de defesa. In: VIEIRA, F. O.; MENDES, A. M.; MERLO, A. R. C. (Org.). Dicionário crítico de gestão e psicodinâmica do trabalho. Curitiba: Juruá, 2013. p. 249- 254.

COLI, J. Vissi d'arte por amor a uma profissão: um estudo de caso sobre a profissão do cantor de teatro lírico. São Paulo: Annablume, 2006.

COSTA, S. H. B. Trabalho prescrito e trabalho real. In: VIEIRA, F. O.; MENDES, A. M.; MERLO, A. R. C. (Org.). Dicionário crítico de gestão e psicodinâmica do trabalho. Curitiba: Juruá, 2013.

DARDOT, P.; LAVAL, C. A nova razão do mundo: ensaio sobre a sociedade neoliberal. São Paulo: Editora Boitempo, 2016.

DEJOURS, J. C. A banalização da injustiça social. 2. ed. Rio de Janeiro: Fundação Getúlio Vargas, 1999.

DEJOURS, J. C. Activisme professionnel: masochisme, compulsivité ou aliénation? Travailler, n. 11, p. 25-40, 2004. DOI:10.3917/trav.011.0025.

DEJOURS, J. C. A Sublimação, entre prazer e sofrimento no trabalho. Revista Portuguesa de Psicanálise. Lisboa, v.33, n.2, p.9-28, 2013.

DEJOURS, J. C. Trabalho vivo: trabalho e emancipação (Tomo II). Brasília: Paralelo 15, 2012.

DEJOURS, J. C. ABDOUCHELI, E., JAYET, C. Psicodinâmica do trabalho: contribuições da escola Dejouriana à análise da relação prazer, sofrimento e trabalho. 1. ed. São Paulo: Atlas, 2014.

DEJOURS, J. C.; BÉGUE, F. Suicídio e trabalho: o que fazer? Brasília: Paralelo 15, 2010.

FERREIRA, J. B. Do poema nasce o poeta: criação literária, trabalho e subjetivação. Rio de Janeiro: 7 Letras, 2011.

FERREIRA, J. B. Patologias da solidão. In: VIEIRA, F. O.; MENDES, A. M.; MERLO, A. R. C. (Org.). Dicionário crítico de gestão e psicodinâmica do trabalho. Curitiba: Juruá, 2013. p. 275- 279.

FUNDAÇÃO GETÚLIO VARGAS. A cultura na economia brasileira. Rio de Janeiro: FGV, 2015.

FREUD, A. O ego e os mecanismos de defesa (1946). Porto Alegre: Artmed, 2006. 
FREUD, S. Os Instintos e seus destinos (1915). In: Obras completas - Introdução ao narcisismo, ensaios de metapsicologia e outros textos (1914-1916). São Paulo: Companhia das Letras, 2010. $12 \mathrm{v}$.

FREUD, S. Além do princípio do prazer (1920). In: Obras completas - História de uma neurose infantil ("O Homem dos Lobos"), Além do princípio do prazer e outros textos (19171920). São Paulo: Companhia das Letras, 2010. 14 v.

FREUD, S. O mal-estar na civilização (1930). São Paulo: Penguin Clasics Companhia das Letras, 2011.

HOPE, S; RICHARDS, J. Loving work: drawing attention to pleasure and pain in the body of the cultural worker. European Journal of Cultural Studies, v.18, n.2, p.117-141, 2015. DOI: 10.1177/1367549414563299.

LIMA, V. S. O trabalho de artistas de um grupo de comédia: análise psicodinâmica do prazer e do enfrentamento do sofrimento. 2009. Dissertação de Mestrado (Mestrado em Psicologia Social, do Trabalho e das Organizações) - Instituto de Psicologia, Universidade de Brasília, Brasília, 2009.

MENDES, A. M. B. Psicodinâmica do trabalho: teoria, método e pesquisas. São Paulo: Casa do Psicólogo, 2007.

MENGER, P-M. Retrato do artista enquanto trabalhador: metamorfose do Capitalismo. Lisboa: Editora Roma, 2005.

MERLO, A. R. C. Processo de globalização, sofrimento psíquico e atenção à saúde mental no trabalho. In: MENDES, A. M. B.; MORAES, R. D.; MERLO., A. R. C. (Org.). Trabalho \& Sofrimento: Práticas Clínicas e Políticas. Curitiba: Juruá, 2014. p. 177184.

MORAES, R. D. de. Sofrimento criativo e patogênico. In: VIEIRA, F. O.; MENDES, A. M. B.; MERLO, A. R. C. (Org.). Dicionário crítico de gestão e psicodinâmica do trabalho. Curitiba: Juruá, 2013. p. 415 - 419.

MONTEIRO, J. K.; MORAES, R. D.; MENDES, A. M.; MERLO, A. R. C. Psicodinâmica do trabalho no Brasil: práticas, avanços e desafios. Curitiba: Juruá, 2017.

NASCIMENTO, M.; DELLAGNELO, E. H. L. Entre a obrigação e o prazer de criar: uma análise psicodinâmica do prazer-sofrimento trabalho artístico. REAd - Revista Eletrônica de Administração, Porto Alegre, v. 24, n. 2, p. 135-166, 2018. DOI: 10.1590/14132311.205.80531.

NASCIMENTO, M.; DELLAGNELO, E. H. L. ; BIROCHI, R. Flexibilidade organizacional e vivências de prazer-sofrimento: um ensaio teórico. Revista Brasileira de Estudos Organizacionais, v. 4, n.2, p. 377-406, 2018. DOI:10.21583/2447-4851.rbeo.2017.v4n2.121. 
“Tu não fazes nada além de arte?” Uma análise psicodinâmica do trabalho artístico

NASCIMENTO, M.; COELHO, M. ; DELLAGNELO, E. H. L. Reconhecimento do trabalho artístico na sociedade de consumo. Revista Pensamento Contemporâneo em Administração (UFF), Rio de Janeiro, v. 12, n.3, p. 65-78, 2018. DOI: 10.12712/rpca.v12i3.13184.

ORGANIZAÇÃO INTERNACIONAL DO TRABALHO. Workplace stress: A collective challenge. Genebra, 2016. Disponível em: <http://www.ilo.org/wcmsp5/groups/public/---ed_protect/--protrav/---safework/documents/publication/wcms_466547.pdf>. Acesso em: 13 de novembro de 2019.

PÉRILLEUX, T. Politique du symptôme. In: MENDES, A. M.; MORAES, R. D.; MERLO., A. R. C. (Org.). Trabalho \& Sofrimento: Práticas Clínicas e Políticas. Curitiba: Juruá, 2014. p. 47 - 64.

SEGNINI, M. P.; LANCMAN, S. Sofrimento psíquico do bailarino: Um olhar da psicodinâmica do trabalho. Revista Laboreal, Porto, v.7, n.1, 2011. DOI: 10.4000/laboreal.8185.

TRANSFORM. Producción cultural y prácticas instituyentes: líneas de ruptura en la crítica institucional. Traficantes de Sueños: Madrid, 2008.

THROSBY, D. Defining the artistic workforce: the Australian experience. Poetics, v. 28, n.4, p. 255-271, 2001. DOI: 10.1016/S0304-422X(01)80003-6.

VAILLANT, G. Adaptative mental mechanisms: their role in a positive psychology. American Psychologist, v. 55, n. 1, p. 89-98, 2000. DOI: 10.1037//0003-066X.55.1.89.

VAILLANT, G. E. Ego mechanisms of defense: a guide for clinicians and researchers. New York: American Psychiatric Press, 1992.

WEBER, M. A Ética protestante e o espírito do capitalismo (1904). 1. ed. São Paulo: Martin Claret, 2013. 